Editorial

\title{
Timing of musculoskeletal steroid injections in pain practice during Coronavirus disease 2019 (COVID-19) vaccine administration
}

\author{
Kyung-Hoon Kim \\ Department of Anesthesia and Pain Medicine, School of Medicine, Pusan National University, Yangsan, Korea
}

Received November 23, 2021, Revised December 1, 2021, Accepted December 2, 2021

Handling Editor: Francis S. Nahm

Correspondence

Kyung-Hoon Kim

Pain Clinic, Pusan National University Yangsan Hospital, 20 Geumo-ro, Mulgeum-eup, Yangsan 50612, Korea

Tel: +82-55-360-1422, Fax: +82-55-360-2149, E-mail: pain@pusan.ac.kr

Patients who are scheduled to get a Coronavirus disease 2019 (COVID-19) vaccine frequently ask whether they may receive a steroid injection for musculoskeletal pain. During the current pandemic, this question is asked more frequently than were questions about cessation of anticoagulants/antiplatelets or having diabetes mellitus before musculoskeletal injections prior to the pandemic.

Currently available COVID-19 vaccines elicit an immune response, producing neutralizing antibodies against the severe acute respiratory syndrome coronavirus 2 (SARS$\mathrm{CoV}-2$ ) spike protein. They include messenger ribonucleic acid (mRNA), adenoviral-vectored, as well as protein subunit and whole-cell inactivated virus vaccines. These vaccines work through 3 steps: 1) antigen phagocytosis, 2) $\mathrm{T}$ cell activation and cytokine production, and 3) cytokine stimulation of B cells to differentiate into plasma cells. All vaccines make immunity through cytokine production $[1,2]$.

Glucocorticoids are widely administered through intraarticular, interfascial, epidural, or bursal injections for musculoskeletal pain, using their anti-inflammatory effects. In addition to an anti-inflammatory effect through the blocking action of inflammatory mediators (transrepression), or by inducing the anti-inflammatory mediators (trans-activation) of glucocorticoids, they have immunosuppressive, anti-proliferative, and vasoconstrictive effects. Focusing on the immunosuppressive effect, it originates from suppression of delayed hypersensitivity reactions by directly affecting T cells [3].

Systemic glucocorticoids can be classified by their duration of action: short-acting (less than 12 hours), such as, hydrocortisone and cortisone, intermediate-acting (12-36 hours), such as, prednisone, prednisolone, methylprednisolone acetate (MPA), and triamcinolone hexacetonide, (TH), and triamcinolone acetate (TA), and long-acting (3672 hours), such as, dexamethasone phosphate (DP), betamethasone sodium phosphate (BSP), and paramethasone. Comparing their anti-inflammatory effect to the shortacting hydrocortisone, the intermediate- and long-acting glucocorticoids show 4-5 and 30 times the effect, respectively [3].

The hypothalamus-pituitary-adrenal (HPA) axis has feedback interactions. The hypothalamus releases corticotropin-releasing hormone (CRH), which affects the anteri- (c) This is an open-access article distributed under the terms of the Creative Commons Attribution Non-Commercial License (http://creativecommons.org/licenses/by-nc/4.0/), which permits unrestricted non-commercial use, distribution, and reproduction in any medium, provided the original work is properly cited.

(C) The Korean Pain Society, 2022
Author contributions: Kyung-Hoon Kim: Writing/manuscript preparation. 
or pituitary gland. The gland releases adrenocorticotropic hormone (ACTH), which affects the adrenal cortex. The adrenal cortex releases cortisol, which produces a negative feedback to the hypothalamus and pituitary gland. Not only endogenous, but also exogenous glucocorticoids exert both early (within minutes) and delayed (2-20 hours) inhibition at the pituitary and hypothalamus levels. The early response occurs from increased glucocorticoid level, resulting in inhibition of the release of ACTH and $\mathrm{CRH}$. However, the delayed response is explained by inhibition of gene transcription factors from pro-opiomelanocortin, leading to decreased synthesis of ACTH. The delayed response is dependent on the dose and duration of glucocorticoid use. A single use of glucocorticoids is sufficient to suppress the HPA axis, but recovery is rapid. Rapid recovery of the HPA axis suppression is ensured through glucocorticoid use within 2 weeks [4].

However, most studies related to HPA suppression, induced by exogenous glucocorticoid administration, are performed through systemic administration, such as oral or intravenous administration. The extent to which HPA axis suppression develops depends on the site of injection, frequency, preparation, and dose of musculoskeletal steroids for pain management [5].

First of all, the dose used in epidural administration of glucocorticoids affects the duration of HPA axis suppression. Measured by morning salivary cortisol, lumbar interlaminar epidural steroid injection with a higher dose (40 mg) of TA showed longer HPA axis suppression (19.7 \pm 3.1 days) compared to with a lower dose $(20 \mathrm{mg}$ for $8.0 \pm$ 2.4 days) [6]. A similar study of serum concentration after lumbar interlaminar epidural steroid injection using TA revealed that the terminal elimination half-life was 21.8 days and peak serum concentration was reached within 1 day [7]. A study related to cervical interlaminar epidural steroid injection, using TA, showed that the terminal elimination half-life was 9.1 days, and peak serum concentration was reached within 22.1 hours [8]. In another study using epidural steroid injections with a dose of 80 mg of MPA, HPA axis suppression continued 2 weeks, and returned to the normal range by 4 weeks [9].

Second, the preparation of glucocorticoids can be divided into particulate steroids, such as MPA, BSP, TH, and TA, and non-particulate steroids, like DP. Particulate glucocorticoids may show a longer duration of action due to a local depot effect, resulting in continuous release of the active drug from the injection site. In addition, particulate glucocorticoid cervical transforaminal epidural injections may carry the risk of paraplegia due to spinal cord infarction resulting from occlusion of the segmental arteries or embolization through the vertebral artery. The particles of MPA, TA, and TH coalesce into large particles, greater than $100 \mu \mathrm{m}$. The coalesced particles may occlude capillaries $(5-8 \mu \mathrm{m})$, meta-arterioles $(20-50 \mu \mathrm{m})$, and arteries $(>50 \mu \mathrm{m})$. The particle size of DP is less than $5 \mu \mathrm{m}$. DP has the lowest density and the least aggregation tendency among the glucocorticoids mentioned above [10].

There are at least 6 United States Food and Drug Administration (US FDA)-approved glucocorticoids for intraarticular injections: TH, TA, MPA, betamethasone acetate (BA), BSP, and DP. The absorption and duration of action of the injectable glucocorticoids is deeply related to its solubility. The order of insolubility is TH, TA, and MPA [5,11].

Third, the site of steroid injection for musculoskeletal pain is significant. After lumbar facet joint injections using TA, its peak serum concentration is reached within 24 hours. The median terminal elimination half-life was 8.9 days, but baseline cortisol levels were suppressed for 4.4 days [12]. Following a single intraarticular injection of 10 20,40 , or $80 \mathrm{mg}$ of MPA into the small-sized joints in the hands, medium-sized joints in the elbows, or large-sized joints in the knees, respectively, a reduced fasting cortisol level was observed from 1 day (48\%) to 2 weeks (4\%) in 25 patients with rheumatoid diseases [13].

A limited number of guidelines or recommendations for steroid injection for musculoskeletal pain during COVID-19 vaccine administration can be found. The American Academy of Orthopaedic Surgeons (AAOS) Patient Safety Committee recommended avoiding musculoskeletal steroid injections 2 weeks before and 1 week after COVID-19 vaccination on September 3, 2021 [14]. The journal Pain Practice recommended delaying musculoskeletal intervention using steroids for 1-2 weeks after vaccine administration [15]. Steroid distancing during COVID-19 was prescribed by the journal Pain Physician, which recommended avoiding the use of epidural or intraarticular steroids during COVID-19 vaccine administration. They recommend use of steroids only after local anesthetics have proved insufficient [16].

Healthcare personnel receive influenza virus vaccine in the early winter every year. Steroid administration did not affect antigen titer formation after influenza virus vaccination in asthmatic children [17].

Acetaminophen, rather than non-steroidal anti-inflammatory drugs, is generally recommended for pain control after COVID-19 vaccine administration due to the lack of antiinflammatory effect, so as not to affect formation of immunity through cytokine production $[18,19]$.

A booster shot 6 months after second dose of the vaccine is waiting for us, and we cannot guess how many times we will have to receive additional booster shots due to weakened immunity or new Coronavirus variants, as with influenza vaccination. Glucocorticoid injections for musculoskeletal pain are generally accepted at 1 week before 
and after COVID-19 vaccine administration [20]. According to the injection site, a different dose and preparation of steroids should be administered, while considering the duration of action, during COVID-19 vaccine administration.

\section{CONFLICT OF INTEREST}

No potential conflict of interest relevant to this article was reported.

\section{FUNDING}

No funding to declare.

\section{ORCID}

Kyung-Hoon Kim, https://orcid.org/0000-0003-3925-8917

\section{REFERENCES}

1. Sadarangani M, Marchant A, Kollmann TR. Immunological mechanisms of vaccine-induced protection against COVID-19 in humans. Nat Rev Immunol 2021; 21: 475-84.

2. Zieneldien T, Kim J, Cao J, Cao C. COVID-19 vaccines: current conditions and future prospects. Biology (Basel) 2021; 10: 960 .

3. Liu D, Ahmet A, Ward L, Krishnamoorthy P, Mandelcorn $\mathrm{ED}$, Leigh $\mathrm{R}$, et al. A practical guide to the monitoring and management of the complications of systemic corticosteroid therapy. Allergy Asthma Clin Immunol 2013; 9: 30.

4. Younes AK, Younes NK. Recovery of steroid induced adrenal insufficiency. Transl Pediatr 2017; 6: 269-73.

5. Johnston PC, Lansang MC, Chatterjee S, Kennedy L. Intraarticular glucocorticoid injections and their effect on hypothalamic-pituitary-adrenal (HPA)-axis function. Endocrine 2015; 48: 410-6.

6. Sim SE, Hong HJ, Roh K, Seo J, Moon HS. Relationship between epidural steroid dose and suppression of hypothalamus-pituitary-adrenal axis. Pain Physician 2020; 23(4S): S283-94.

7. Hooten WM, Nicholson WT, Gazelka HM, Reid JM, Moeschler SM, Lamer TJ. Serum triamcinolone levels following interlaminar epidural injection. Reg Anesth Pain Med 2016; 41: 75-9.

8. Lamer TJ, Dickson RR, Gazelka HM, Nicholson WT, Reid JM, Moeschler SM, et al. Serum triamcinolone levels following cervical interlaminar epidural injection. Pain Res Manag
2018; 2018: 8474127.

9. Abdul AJ, Ghai B, Bansal D, Sachdeva N, Bhansali A, Dhatt SS. Hypothalamic pituitary adrenocortical axis suppression following a single epidural injection of methylprednisolone acetate. Pain Physician 2017; 20: E991-1001.

10. Makkar JK, Singh PM, Jain D, Goudra B. Particulate vs nonparticulate steroids for transforaminal epidural steroid injections: systematic review and meta-analysis of the current literature. Pain Physician 2016; 19: 327-40.

11. Derendorf H, Möllmann H, Grüner A, Haack D, Gyselby G. Pharmacokinetics and pharmacodynamics of glucocorticoid suspensions after intra-articular administration. Clin Pharmacol Ther 1986; 39: 313-7.

12. Dickson RR, Reid JM, Nicholson WT, Lamer TJ, Hooten WM. Corticosteroid and cortisol serum levels following intraarticular triamcinolone acetonide lumbar facet joint injections. Pain Pract 2018; 18: 864-70.

13. Mader R, Lavi I, Luboshitzky R. Evaluation of the pituitaryadrenal axis function following single intraarticular injection of methylprednisolone. Arthritis Rheum 2005; 52: 924-8.

14. American Academy of Orthopaedic Surgeons Patient Safety Committee. Timing of musculoskeletal cortisone injections and COVID vaccine administration [Internet]. Rosemont (IL): American Academy of Orthopaedic Surgeons; 2021. Available at: https://www.aaos.org/about/covid-19-informationfor-our-members/guidance-for-elective-surgery/timing-ofmusculoskeletal-cortisone-injections-and-covid-vaccineadministration/.

15. Chow RM, Rajput K, Howie BA, Varhabhatla N. The COVID-19 vaccine and interventional procedures: exploring the relationship between steroid administration and subsequent vaccine efficacy. Pain Pract 2021; 21: 966-73.

16. Manchikanti L, Kosanovic R, Vanaparthy R, Vangala BP, Soin A, Sachdeva $\mathrm{H}$, et al. Steroid distancing in interventional pain management during COVID-19 and beyond: safe, effective and practical approach. Pain Physician 2020; 23(4S): S319-50.

17. Fairchok MP, Trementozzi DP, Carter PS, Regnery HL, Carter ER. Effect of prednisone on response to influenza virus vaccine in asthmatic children. Arch Pediatr Adolesc Med 1998; 152: 1191-5.

18. Kim KH, Seo HJ, Abdi S, Huh B. All about pain pharmacology: what pain physicians should know. Korean J Pain 2020; 33: 108-20.

19. Chen JS, Alfajaro MM, Chow RD, Wei J, Filler RB, Eisenbarth SC, et. al. Non-steroidal anti-inflammatory drugs dampen the cytokine and antibody response to SARS-CoV-2 infection. J Virol 2021; 95: e00014-21.

20. Hong SM, Park YW, Choi EJ. Steroid injections in pain management: influence on Coronavirus disease 2019 vaccines. Korean J Pain 2022; 35: 14-21. 